\title{
A metáfora na área econômica
}

\author{
Ana Cláudia de Souza \\ Universidade Federal de Santa Catarina \\ Universidade do Extremo Sul Catarinense
}

\section{Abstract}

This study analyses the simple and compound metaphorical lexical units that constitute the keyword list of the economic news genre. The analysed texts are taken from the newspaper Folha de São Paulo, and are part of the corpus compiled by NILC - Núcleo Interinstitucional de Lingüística Computacional. The complete corpus is constituted by prose texts from several social domains, among which the journalistic one. Although news is considered as an informational speech genre in which the referential function of language predominates, the use of metaphorical expressions is found in this kind of text. The theoretical background, considering speech genre in the light of Bakhtin's theory, and concepts of news and metaphor, is presented in the first section of the paper. Then, the methodological criteria are described, and the set of data is presented and discussed. 


\section{INTRODUÇÃO}

$\mathrm{N}$

a esfera jornalística, a notícia é entendida como um gênero discursivo de informação, em que há predominância da função referencial. O intuito de quem produz esta modalidade de texto é registrar e expor fatos ou acontecimentos revestidos do caráter de novidade, sem imprimir suas opiniões explicitamente.

Neste estudo, realiza-se uma análise de corpus, composto por notícias econômicas publicadas no jornal Folha de São Paulo, veículo de ampla circulação nacional, com grande tiragem, no qual o uso da norma padrão escrita é privilegiado.

A pesquisa é conduzida com o auxílio do Programa WordSmith, destinado à realização de análises estatísticas. O objetivo é investigar o emprego de expressões metafóricas neste gênero do discurso. A hipótese que conduz esta pesquisa é a de que mesmo em textos mais referenciais, como estes do gênero discursivo de informação, a possibilidade de ocorrência de expressões metafóricas é bastante grande.

\section{REFERENCIAL TEÓRICO}

\subsection{Visão bakhtiniana de gênero do discurso}

Na perspectiva bakhtiniana (BAKHTIN/VOLOSHÍNOV, 1981; FREITAS, 1996; RODRIGUES, 2000), o homem é um sujeito social da e na história. O que o distingue dos demais animais é a linguagem, resultado da atividade humana coletiva, surgida a partir das necessidades de comunicação social. Isso a caracteriza como "um 
fenômeno sócio-ideológico, apreendido no fluxo da história" (RODRIGUES, 2001a: 16).

A comunicação deve ser entendida como um meio de interação entre o homem e a sociedade. Na concepção de Bakhtin/Voloshínov (1981), o outro é a condição da identidade, da constituição e do desenvolvimento dialógico dos muitos eus. Essa relação entre a alteridade e o eu acontece por meio da linguagem.

Do vasto universo da linguagem, a palavra, ou seja, a linguagem verbal, é o mais poderoso dos instrumentos semióticos usado no contato e na interação social, exercendo função fundamental na vida social e na formação dos sistemas ideológicos e da consciência dos homens. Segundo Bakhtin/Voloshínov (1981: 36, grifo do autor), " $A$ palavra é o fenômeno ideológico por excelência”. Além disso, é o meio pelo qual se organiza o pensamento e se planeja a ação.

O sentido da palavra ou a sua mensagem somente podem ser alcançados por meio do contexto, em condições concretas de enunciação, em uma relação constitutiva com o outro, pois cada enunciado acontece como resposta a enunciados anteriores e está direcionado a uma resposta ativa do interlocutor (leitor ou ouvinte).

O enunciado é entendido como unidade concreta e irrepetível da comunicação discursiva, que representa um elo na cadeia comunicativa contínua; portanto, não pode ser visto fora da situação social (RODRIGUES, 2001b). A construção do enunciado se dá a partir de um querer dizer e da noção de gênero do discurso conhecida, muitas vezes implicitamente, pelo sujeito, para uma determinada situação de interação. Como unidade real, o enunciado precisa da língua para se realizar; é por meio da língua que ele se concretiza. Um enunciado não existe senão em uma situação discursiva ou construído em um determinado gênero (RODRIGUES, 2001c).

De acordo com a teoria bakhtiniana (RODRIGUES, 2001b), os gêneros são as unidades concretas da comunicação e interação humanas e se realizam de modo relativamente estável. Trata-se de uma das grandes forças de estratificação da língua. Diferentemente dos enunciados, os gêneros não são individuais e irrepetíveis. Cada 
gênero do discurso é construído sócio-historicamente sobre determinado cronotopo: tempo, lugar e homem histórico, assim como sobre um horizonte axiológico e um suporte material de veiculação pré-definidos.

A construção e a execução do discurso são antecedidas pela totalidade do enunciado, considerando-se a intenção e a interação discursiva do indivíduo e o gênero específico, uma vez que o gênero do discurso não pode ser escolhido: a situação de interação é que o determina. Quando se tem finalidade, destinatário e conteúdo, em uma situação de interação, já está determinado o gênero. A noção de gênero é estabelecida pela situação social em que o ato da comunicação está inserido, que cria expectativas no interlocutor: não lemos uma carta comercial como se estivéssemos lendo uma carta familiar, escrita por um amigo. Enquanto para o leitor, o gênero cria um universo de expectativas, para o escritor, ele é um modelo de referência a partir do qual seu texto deve ser produzido.

Tendo por base as concepções de enunciado e gênero do discurso brevemente esboçadas, será apresentada, na próxima seção, a concepção de notícia jornalística.

\subsection{O gênero jornalístico notícia'}

Considerando a abordagem sócio-histórica da constituição e do funcionamento dos gêneros desenvolvida por Bakhtin, existem diferentes esferas sociais em que se organizam e agrupam os gêneros do discurso. Uma determinada intenção comunicativa, em contexto e situações de interação específicos e em condições determinadas, produz gêneros do discurso particulares a uma esfera social.

Historicamente, cada esfera social desenvolve seus próprios gêneros, os quais carregam, nas suas dimensões constitutivas, as condições e a finalidade da esfera à qual pertencem. As especificidades da constituição e do funcionamento de cada um dos gêneros estão relacionadas às características das situações de comunicação discursiva das esferas sociais das quais fazem parte. 
As esferas não são instâncias geográficas e não têm fronteiras precisas, entrecruzando-se a todo momento. Com relação à esfera jornalística, Melo (1985: 7) afirma que há mais de um século ela está sendo pesquisada, mas isso não foi suficiente para conceituá-la precisamente, pois o jornalismo se alimenta essencialmente daquilo que é efêmero e circunstancial, exigindo do cientista perspicácia na sua caracterização para não ser enredado pelo transitório.

Não é possível estabelecer, de modo estanque, o que separa um gênero de outro, pois suas fronteiras são difusas. Todavia, podese definir alguns critérios para identificar os gêneros, pelo menos quanto aos textos que se situam um pouco mais distantes dos supostos limites genéricos.

Com relação à notícia, na esfera jornalística, trata-se de um gênero do discurso que faz parte da categoria do jornalismo informativo. Ela tem por objetivo informar o leitor, por meio de um relato ou exposição integral de um fato novo, atual, efêmero, sem discuti-lo ou analisá-lo. O efeito discursivo de referencialidade, neutralidade e objetividade são fundamentais à notícia, o que não significa que ela seja desprovida de orientação valorativa. Não seria adequado, por isso, que se falasse em referencialidade, neutralidade e objetividade no sentido estrito dos termos. Na concepção de Gutierrez Palacio (1984), não há texto periódico puramente informativo e objetivo.

Lage (1998a: 16) entende a notícia, no jornalismo moderno, como o "relato de uma série de fatos a partir do mais importante ou interessante; e de cada fato, a partir do aspecto mais importante ou interessante", levando à concepção jornalística de pirâmide invertida.

Segundo este autor (1998a: 22-26), existem, na notícia, as seguintes restrições pragmáticas da relação entre jornalista e público, muitas delas podendo ser estendidas a toda a linguagem jornalística (LAGE, 1998b: 36-48):

- limitação do código, o que aumenta a comunicabilidade e facilita a produção textual; 
- redator não conhecido do leitor, mesmo quando assina o texto (Assinar o texto é um procedimento bastante incomum.);

- uso da terceira pessoa, comumente no modo indicativo, efeito que favorece a impessoalidade;

- retórica referencial, focalizando a mensagem e reportandose ao mundo objetivo, exterior ao processo de comunicação;

- ênfase na verdade, adaptando os enunciados aos fatos. A notícia é axiomática, ou seja, diz-se verdadeira. Não há argumentação, conclusão nem sustentação de hipótese;

- demonstração da verdade, evitando referências imprecisas, já que ser verdadeiro não é suficiente.

Para Lage (1998a: 31), a notícia é definida como "o relato de deslocamentos, transformações e enunciações observáveis no mundo e consideradas de interesse para o público". Sodré e Ferrari (1982: 7) propõem uma outra definição de notícia que não se contrapõe à anteriormente citada. Na perspectiva desses autores, notícia seria "todo fato social destacado em função de sua atualidade, interesse e comunicabilidade. Deve ser comunicada de forma direta, concreta, objetiva, de modo adequado às possibilidades práticas do veículo comunicador".

Martínez Albertos (1974: 32-38), a partir da proposta de Dovifat, afirma que as características distintivas do estilo informativo são: concisão, clareza e construção que captem a atenção do leitor.

Quanto à composição, a notícia é constituída pelo lide ${ }^{2}$ e pelo desenvolvimento dos aspectos mencionados, de forma eficaz e altamente objetiva e concisa, no lide. O lide tem a função de introduzir o leitor no texto e captar sua atenção. Trata-se de breve síntese da notícia em seu primeiro parágrafo (FOLHA DE SÃO PAULO, 2000; O GLOBO, 1999; GUTIERREZ PALACIO, 1984: 107).

Como nosso intuito é analisar aspectos da metáfora nas notícias jornalísticas voltadas à economia, na próxima seção, serão apresentadas as bases teóricas acerca da metáfora sobre as quais os dados do estudo serão discutidos. 


\subsection{A metáfora}

De acordo com Bakhtin/Voloshínov (1981: 128-136), cada enunciado possui um sentido próprio, único, irrepetível e bem definido: o tema. O tema não é alcançado senão por meio do enunciado como um todo, que se realiza em situações de interação social e discursiva reais. O que determina o tema não são somente os aspectos lingüísticos, que constituem a sua concretização comunicativa, mas também os fatores não verbais envolvidos na interação. Além do tema, o enunciado também possui significação. Esta, por sua vez, é repetível e pode ser idêntica sempre que empregada. Trata-se de um elemento abstrato, que não tem existência concreta. Pode-se, por exemplo, falar da significação de uma palavra, mas não de seu tema, a menos que a palavra tenha sido promovida a enunciado numa dada situação.

A partir dessa concepção, Bakhtin/Voloshínov defendem que não é satisfatória a análise do sentido usual e ocasional ou denotativo e conotativo. Estando no campo inferior da significação, é possível que se trate dos elementos dessa maneira, mas quando se está no campo do tema, não. No estágio superior, o contexto e a situação de interação direcionariam a construção de determinado sentido único e não reiterável.

As contribuições de Bakhtin/Voloshínov são de grande importância ao estudo da linguagem e seu emprego em situações discursivas concretas. Todavia, acredita-se que seja possível tratar parte do enunciado ou o todo enunciativo metaforicamente. No primeiro caso, teríamos o estudo da significação e, no segundo, do tema. Aceita-se essa possibilidade com base na concepção de metáfora a partir da transposição de propriedades entre domínios (LAKOFF \& JOHNSON, 1980).

Desde Aristóteles, diferentes papéis têm sido atribuídos à metáfora. Ela foi considerada um recurso dissociado da linguagem cotidiana. Seu emprego revelava intenções retóricas, lapso na competência lingüística, figura de estilo.

Por meio da literatura, pode-se observar que a metáfora tem perdido o estigma de linguagem imprópria ou ornamento. Ela hoje 
é vista como um meio de transmitir e adquirir conhecimento (GRIMM-CABRAL, 1994). De acordo com Lakoff e Johnson (1980), Gibbs (1994), Grimm-Cabral (1994), entre outros, a metáfora faz parte do nosso entendimento de mundo. Ela está tão enraizada na linguagem, que nós nem percebemos quando a empregamos. Tratase de um aspecto da constituição da nossa cultura.

Embora diferentes sentidos possam ser atribuídos às expressões metafóricas, não as percebemos normalmente como diferentes das expressões literais, dada a familiaridade com o seu emprego e a sua interiorização.

Sob esta perspectiva, a metáfora é vista como o mapeamento seletivo de propriedades de um domínio conceitual fonte em um domínio alvo. Grimm-Cabral (2000: 53) define a metáfora como "o resultado de um processo cognitivo através do qual o escritor, ao se referir a um elemento X, usa a denominação do elemento Y". Esse processo conduz à superposição de dois ou mais esquemas conceituais, levando à suspensão de conceitos ordinários envolvidos e ao rearranjo do esquema conceitual. Para interpretar a metáfora, o leitor tem que perceber o jogo de faz-de-conta sugerido pelo autor e aceitar a tarefa de produzir novo sentido. A superposição pretendida e construída pelo autor pode ser diferente da percebida pelo leitor.

Lakoff e Johnson (1980) assumem que nosso sistema conceitual ordinário é metafórico e que uma maneira de identificar os conceitos de acordo com os quais nós vivemos é a análise do nosso uso da linguagem. Propondo a existência de metáforas conceituais por meio das quais o pensamento é possibilitado, eles acreditam que as pessoas rotineiramente usam mapeamentos conceituais para entender expressões convencionais no discurso cotidiano. As metáforas conceituais são resultado de uma forma de ação e de pensamento. Entre os exemplos sugeridos pelos autores, há: 1. A DISCUSSÃO É UMA GUERRA ${ }^{3}$, que poderia refletir-se na linguagem cotidiana por meio de grande variedade de expressões metafóricas: "Ele atacou cada ponto fraco de meu argumento", "Destruí o argumento dele", etc.; 2. A INFLAÇÃO É UMA ENTIDADE resultaria 
em expressões como: "A inflação me deixa doente", "Precisamos combater a inflação".

Dessa forma, o raciocínio metafórico levaria à utilização de um domínio de experiência fonte (GUERRA, ENTIDADE) em um domínio de experiência alvo (DISCUSSÃO, INFLAÇÃO). Assim, Lakoff e Johnson propõem o Princípio da Invariabilidade, segundo o qual, embora exista supremacia do domínio fonte, já que sua estrutura limita o mapeamento, nem todos os seus itens lexicais podem ser aplicados a um domínio alvo. Nas palavras de Malta (2000: 23): "Só pode ser mapeado de um domínio para o outro o que preserva as características inerentes a cada domínio".

Lakoff e Johnson acreditam que a essência da metáfora está em entender e empregar um conceito em termos de outro e que organizamos os conceitos fundamentais de nossa cultura em metáforas convencionais, nomeadas metáforas estruturais, ontológicas e orientacionais. Nas metáforas estruturais, um conceito é estruturado metaforicamente em termos de outro (Ex.: Tempo é dinheiro.). As metáforas orientacionais organizam um sistema de conceitos com respeito a um outro. Há vínculo entre conceitos e orientações espaciais tais como up-down, front-back, on-off, in-out, deepshallow, central-peripherical. Essas orientações metafóricas estão baseadas em nossa experiência física e cultural, não se tratando, portanto, de questões arbitrárias (Ex.: A alta do preço dos produtos). Nas metáforas ontológicas, conceitos não físicos - eventos, atividades, emoções, idéias, etc. - são entendidos como entidades e substâncias a partir de nossa experiência com objetos físicos (Ex.: Aluguéis freiam queda da inflação). Personificação é exemplo óbvio de metáfora ontológica, pois objetos físicos são especificados como se fossem humanos (Ex.: Nosso maior inimigo é a inflação). No emprego e na compreensão da metáfora, é importante considerar a função imaginária da linguagem. A expressão metafórica, se entendida literalmente, não é coesa nem coerente.

Segundo Grimm-Cabral (1994), enquanto o leitor, por meio da metáfora, reconceitualiza o mundo, o escritor a emprega com uma das seguintes intenções: 
a) ajudar o leitor a compreender um conceito considerado difícil;

b) expressar uma perspectiva de mundo diferente daquela convencionalmente expressa no código (Pode revelar aspectos ideacionais, estéticos e culturais do seu autor.);

c) promover-se, dificultando a compreensão da expressão metafórica (A relação entre o tópico e o veículo pode ser restrita ao autor ou a um grupo de pessoas que possuem aquele conhecimento específico.);

d) utilizar ferramenta retórica. (As metáforas podem ser ferramentas políticas no sentido de esconder ou mostrar aspectos da realidade.)

Nas notícias jornalísticas, tópico (domínio alvo) e veículo (domínio fonte) compartilham muitos traços; existem estruturas similares entre os domínios em questão. A metáfora parece ser usada, nestes casos, com o intuito de revelar, por meio de noções concretas, realidades abstratas. Na concepção de Grimm-Cabral (1994: 45): "In expository texts, metaphors are a resource that writers have to make use of in order to help the understanding of highly abstract concepts."

Nesta pesquisa, investiga-se a metáfora nas palavras-chave da notícia econômica. Como escritor e leitor sabem, previamente, de que gênero se trata, as metáforas são produzidas e compreendidas dentro dos limites desse gênero, o que facilita seu emprego e compreensão. O que analisamos, precisamente, é a significação dos usos metafóricos das palavras-chave em sua relação imediata com o contexto mais próximo, considerando a transferência de traços entre domínios, como veremos na análise dos dados (cf. seção 2.2).

De acordo com Abreu (1997: 67) - com base em McLuhan (1964) - a metáfora pode ser considerada, no caso da esfera jornalística, como um meio de esfriamento do discurso, uma vez que facilita a compreensão. Conforme esta abordagem, os meios de comunicação são classificados como frios ou quentes. Os meios quentes seriam aqueles em que há concentração de tensão e complexidade, e os meios frios, por sua vez, seriam os que diluem 
essa tensão, veiculando textos com menor grau de complexidade. Para exemplificar um meio quente, ele cita a revista científica, e um meio frio, a televisão. Essa concepção de meios frios e quentes é transportada aos textos. Assim, textos que abordam, de um certo modo, um mesmo assunto podem ter diferentes "temperaturas", dependendo do gênero do discurso, do propósito do autor, do veículo e do destinatário.

É evidente que um texto frio é muito mais facilmente compreendido que um texto quente. Mas vale ressaltar que existe a possibilidade de o autor produzir um texto concebendo-o frio, e o leitor recebê-lo quente. Isso pode ocorrer pelo fato de as experiências dos comunicantes com o assunto serem distintas. O contrário também acontece: o autor produz um texto complexo, e o leitor o compreende rápida e facilmente, por ser especialista, grande conhecedor do assunto.

A metáfora, nesta concepção, é vista como um "processo de esfriamento", por tratar-se de um recurso que auxilia o leitor a compreender o texto, que concretiza aspectos abstratos desenvolvidos na trama textual e que torna o texto mais vivaz e próximo ao interlocutor.

Segundo Abreu (1997: 74), a economia é a área em que este recurso é fortemente utilizado:

[...] Talvez porque a única maneira de digerir o economês seja traduzi-lo em uma linguagem mais acessível ao repertório do leitor comum. A utilização das metáforas tem exatamente esta função: procurar pescar no repertório de um leitor uma imagem de que ele se possa servir para entender o conteúdo proposicional de um texto.

Para exemplificar, Abreu cita, entre outras, algumas manchetes de revista: "A economia brasileira na corda bamba"; "Sem controlar o déficit público, vamos ficar enxugando gelo com medidas paliativas".

Um aspecto do texto de Abreu que nos parece incoerente é a distinção entre metáfora e não-metáfora, como recurso de esfriamento textual. Para o autor: 
Dizer, por exemplo, para o cidadão comum que as altas taxas de juro estão colocando em perigo a contenção da inflação e que o 'ministro da Fazenda parece não ter condições de resolver esse urgente problema', pode ser quente demais. Dizer, entretanto, que 'as taxas de juro colocaram a inflação na marca do pênalti e que o ministro da Fazenda não tem a menor chance de pegar essa bola' esfria bastante a mensagem, uma vez que qualquer brasileiro tem em seu repertório as regras de futebol e sabe muito bem o perigo representado por uma cobrança de penalidade máxima. (ABREU, 1997: 74)

Acredita-se que tanto no primeiro quanto no segundo exemplo houve esfriamento do texto. Há expressões metafóricas também no primeiro caso. Vejamos:

1a. A expressão "altas taxas de juro" pode ser entendida como metáfora pelo fato de os juros não serem, realmente, altos ou baixos. Eles oscilam, mas não em termos de desníveis verticais, que definem altura. Acredita-se que esse emprego se deva ao fato de as análises partirem de bases gráfico-estatísticas, o que permite que se visualize a oscilação dos juros, da inflação, dos preços, etc.

1b. "As altas taxas de juro estão colocando em perigo a contenção da inflação" seria metafórico no sentido de que "colocar em perigo", neste contexto, significa dificultar a manutenção da taxa da inflação em índices menores. Além disso, "as altas taxas de juro” por si só não representam ameaça física concreta. Existe uma série de mecanismos implícitos a esta questão que dificultam a manutenção do índice de inflação.

1c. Há, ainda, a "contenção da inflação". Inflação é um conceito abstrato e, como tal, ela não poderia ser contida. Para interpretar essa expressão, é necessário que se entenda a inflação como uma entidade, como propõem Lakoff e Johnson (1980).

Quanto ao segundo exemplo apresentado por Abreu (1997), sem dúvida, trata-se de metáfora, mas talvez ele não seja mais frio que o anterior, por pressupor conhecimento das regras do futebol. Ao contrário do que afirma o autor, acredita-se que nem todos os 
brasileiros necessariamente conhecem as regras desse esporte. Sob este ponto de vista, supõe-se que o primeiro exemplo possa ser mais facilmente compreendido e atinja um maior número de leitores que o segundo. Esta hipótese mereceria ser testada, embora não nos tenhamos proposto a realizar aqui esse tipo de investigação.

Na próxima seção (item 2.2), discutiremos metáforas semelhantes às do caso 1, a partir da análise de uma amostra do corpus de notícia econômica.

\section{ANÁLISE DO CORPUS}

\subsection{Metodologia}

Nesta pesquisa, realiza-se análise da metáfora no gênero do discurso notícia, utilizando parte do corpus do português escrito, compilado pelo NILC - Núcleo Interinstitucional de Lingüística Computacional. Este corpus contém cerca de 35 milhões de palavras, que constituem textos em prosa provenientes de diversas esferas sociais, entre elas: jornalística, escolar, jurídica, acadêmica, científica, artística, da propaganda e do comércio. O material organizado é de natureza textual real, ou seja, não se trata de textos artificiais, manipulados e desenvolvidos para fins de pesquisa.

Considerou-se como corpus de referência todo o material disponível do jornal Folha de São Paulo, que é composto por publicações dos anos de 94, em sua maioria, e 96. O corpus de análise é constituído de uma amostra do gênero notícia do Caderno Folha Dinheiro desse mesmo periódico. Coletou-se, manualmente, a amostra de notícias, respeitando os seguintes critérios:

a) 1 arquivo do Caderno Folha Dinheiro a cada 8, totalizando 46 arquivos, já que o total de arquivos é de 368;

b) $1^{\mathrm{o}}$ e $2^{\mathrm{o}}$ textos com traços definidos do gênero notícia de cada arquivo selecionado, somando 92 notícias.

Realizada a seleção da amostra, utilizaram-se as ferramentas do WordSmith, que é um conjunto de programas desenvolvido para 
analisar estatisticamente o comportamento e o emprego das palavras nos textos: Wordlist, Concord e Keywords. Por meio do Wordlist, é possivel visualizar todas as palavras ou agrupamentos de palavras num texto, em ordem alfabética ou de freqüência. O Concord permite que se veja qualquer palavra ou agrupamento selecionado, no contexto de ocorrência num corpus escolhido, o que possibilita a observação do tipo de acompanhamento das palavras ou expressões em análise. O Keywords, por sua vez, encontra as palavras-chave num dado corpus. Palavras-chave são aquelas cuja freqüência é alta em comparação a um corpus de referência. Este programa compara duas listas de palavras pré-existentes - geradas pelo Wordlist-, uma maior, que é o corpus de referência, e outra menor, que é o corpus de análise. O objetivo do Keywords é encontrar quais palavras caracterizam o texto ou o conjunto de textos estudado, utilizando um índice baseado na comparação das freqüências das palavras em dois corpora, chamados corpus de análise e corpus de referência, e na probabilidade dessa freqüência percentual ser devida ao acaso (BERBER-SARDINHA, 2001). Este índice é chamado, no presente trabalho, de grau de saliência, tradução em português do termo keywordness. Trata-se de uma medida que expressa numericamente o quanto a palavra em questão é chave no corpus de análise.

Assim, empregaram-se, nesta análise, os programas do WordSmith para gerar as listas de palavras dos corpora de referência e análise (Wordlist), para comparar estas listas, identificando as palavras-chave do corpus de análise (Keywords), e para buscar os contextos de ocorrência de algumas palavras-chave em todo o corpus de análise (Concord).

A partir da lista de palavras-chave gerada pelo Keywords e do seu grau de saliência nos textos analisados, selecionaram-se nove para realizar a análise a que nos propomos nesta pesquisa. A escolha das palavras-chave se deu aleatoriamente, eliminados nomes próprios, marcas, siglas, verbos, adjetivos e preposições. Todas as palavras selecionadas são empregadas na função de substantivo nos textos analisados. Realizou-se concordância das nove palavras 
selecionadas e, então, procedeu-se a uma análise manual para classificar as ocorrências como metafóricas ou não-metafóricas.

A apresentação, análise e discussão dos dados é conduzida na próxima seção.

\subsection{Apresentação e discussão dos dados}

Decidiu-se analisar algumas das palavras-chave do gênero notícia do caderno de economia, por acreditar que essas seriam as palavras que melhor representariam a parcela lexical desse gênero do discurso, dada a sua saliência em relação às demais unidades e expressões do texto. Considerou-se metáfora toda expressão em que houvesse a denominação $\mathrm{X}$ em referência ao elemento $\mathrm{Y}$, com transposição de traços de um domínio-fonte a um domínio-alvo (LAKOFF e JOHNSON, 1980; GRIMM-CABRAL, 1994, 2000; MALTA, 2000).

Como demonstrado na tabela a seguir, foram selecionadas nove palavras-chave. Entre os contextos de ocorrência dessas unidades, gerados pela ferramenta Concord, predominou o uso metafórico, o que não significa que a metáfora seja predominante nesse gênero do discurso. Trata-se simplesmente da análise de um certo número de casos em relação à significação das palavras em contextos específicos. Em uma análise mais ampla, em que se considerasse o tema, ou seja, a situação de interação como um todo, os resultados poderiam, eventualmente, ser diferentes. Existe ainda a possibilidade de predomínio do emprego não metafórico relacionado ao uso das demais palavras-chave da notícia econômica.

É importante destacar que foram identificadas somente metáforas convencionais, como se pode verificar observando os exemplos fornecidos ao longo desta seção. Acredita-se que não foram encontradas metáforas novas, porque a busca foi conduzida pela identificação da palavra-chave, ou seja, analisaram-se apenas as ocorrências metafóricas relacionadas a estas palavras. É provável que em uma investigação que partisse de critérios diferentes se encontrassem metáforas novas ou deliberadas. 
No quadro abaixo, são apresentadas as palavras-chave, segundo o grau de saliência, seguidas das respectivas ocorrências em termos de emprego metafórico vs não-metafórico:

\begin{tabular}{|c|c|c|c|c|}
\hline Grau de saliência & Palavra-chave & Metáfora & Não-metáfora & Totais \\
\hline 1 & Produto & 39 & 41 & 80 \\
\hline 2 & Mês & 0 & 94 & 94 \\
\hline 3 & Preço & 66 & 65 & 131 \\
\hline 4 & Mercado & 39 & 48 & 87 \\
\hline 7 & Alta & 48 & 0 & 48 \\
\hline 14 & Queda & 45 & 0 & 45 \\
\hline 15 & Cesta & 27 & 0 & 27 \\
\hline 22 & (Des)aceleração & 18 & 0 & 18 \\
\hline 54 & Inflação & 33 & 10 & 43 \\
\hline Totais & & 315 & 258 & 573 \\
\hline
\end{tabular}

Como pode ser constatado por meio desse quadro de valores, das palavras selecionadas, mês foi a única que não apresentou ocorrências metafóricas, pois seu emprego ocorre sempre em referência à localização temporal, num período de mais ou menos 30 dias:

Ex. 14: "No acumulado do mês, a cesta registra queda de 0,66\%. A maior redução do mês é dos produtos de limpeza, que caíram 4,31\%."

As palavras-chave alta, queda, aceleração ou desaceleração e cesta foram caracterizadas como metafóricas, em todos os exemplos, independentemente da sua relação com o elemento predicativo, pois a maneira como as oscilações econômicas são concebidas pressupõe um mapeamento entre dois domínios conceituais. Existe sempre a noção gráfico-estatística de quantificação, como se pode verificar por meio dos exemplos: 
Ex. 2a: "Reajustes chegam a 12,27\% esta semana contra $8,08 \%$ na anterior; URV e alimentos puxam alta."

Ex. 2b: "Os remédios continuam em alta. Nos últimos 30 dias terminados em 15 de janeiro, ficaram 42,33\% mais caros, em média."

Ex. 3a: "A transferência de parte da produção do Gol para a unidade da Autolatina em São Bernardo foi a responsável pela queda no volume de fabricação do carro, segundo a Volks."

Ex. 3b: "A queda do ritmo da inflação e dos juros dará à caderneta de poupança, este mês, a liderança no ranking das aplicações financeiras."

Ex. 4a: "Os produtos de elaboração primária, como carnes e cereais, tiveram a maior aceleração no IPCA."

Ex. 4b: "A desaceleração ocorreu principalmente entre os alimentos semi-elaborados $(37,65 \%)$ e produtos 'in natura' (30,69\%)."

Nestes exemplos, fala-se em alta (2a e b) referindo-se, metaforicamente, à dimensão de um corpo considerado em termos de suas evoluções em sentido vertical, situado em um ponto superior ao de referência e posterior em relação à linha do tempo. Queda (3a e b) carrega a mesma noção, só que o ponto de referência é superior ao ponto em que está o elemento do qual se fala. Aceleração e desaceleração, neste contexto, não têm o sentido de aumento ou diminuição da velocidade. Os valores aqui se aproximam daqueles de alta e queda. A diferença entre alta/queda e aceleração/ desaceleração é a de que estes ( $4 \mathrm{a}$ e b) não revelam necessariamente oscilação de valor superior ou inferior em relação à referência fixa, mas, sim, em relação às oscilações anteriores. Em todos esses casos (2, 3 e 4), não existe um corpo concreto. Faz-se a concretização de elementos abstratos - preço, produtos, volume de fabricação, ritmo da inflação, etc.-, por meio de um mapeamento a partir do domíniofonte: gráfico-estatístico. Os preços, por exemplo, sobem, descem, aceleram ou desaceleram nas linhas que traçam o gráfico. Os jogos metafóricos que tomam por base a noção de gráfico delineiam essa 
noção de maneira clássica: oscilação marcada bidimensionalmente no eixo das ordenadas e oscilação marcada em função do tempo no eixo das abscissas. No gráfico estatístico de que falamos, os dados são registrados da esquerda para a direita (tempo progressivo) e com linhas ascendentes e descendentes (valor monetário).

Nos dados desta pesquisa, há uma série de unidades lexicais e expressões da língua que portam, de modo intrínseco, a noção de up e down, o que seria considerado por Lakoff e Johnson (1980) como metáfora orientacional:

Up: $\quad$ alta, aceleração, elevação, aumento, escalada; subir, crescer, avançar, aumentar, elevar, deslanchar.

Down: queda, desaceleração, recuo, baixa, redução, retração, recuar, descer, diminuir.

Ausência de oscilação: estabilização, congelamento, estabilidade.

Nos casos em que cesta ( 5 a e b) é a palavra-chave, encontramse somente expressões metafóricas nos dados, porque sempre que esse vocábulo é empregado, ele significa cesta básica: "grupo de bens essenciais à subsistência de uma família de quatro pessoas durante um mês, composto de itens alimentares básicos, higiene e limpeza" (HOUAISS e VILLAR, 2001: 682). Não há a idéia de cesta como um "utensílio próprio para a guarda de objetos diversos". Em termos da economia, não existe a concepção de cesta/objeto concreto, embora o emprego de cesta básica possa ter surgido daí:

Ex. 5a: "Este é o maior preço desde 19 de julho passado, quando o custo da cesta ficou em R $\$ 104,40$. Em uma semana, a cesta acumula alta de 2,9\%."

Ex. 5b: "Desde o início do mês o custo da cesta vem caindo, mas nas segundas-feiras sempre são registrados aumentos devido à suspensão das promoções. O valor da cesta passou de $\mathrm{R} \$ 103,28$, na sexta-feira, para $\mathrm{R} \$ 103,68$ ontem." 
Quanto às demais palavras-chave - produto, preço, mercado e inflação -, elas ora são empregadas em sentido metafórico, ora não, dependendo do contexto ao qual pertencem. Os exemplos seguintes revelam usos metafóricos, bastante comuns, dessas palavras:

Ex. 6a: "Foi o maior crescimento de uma categoria de produtos desde que o IBGE iniciou a atual série de acompanhamento, em 1982."

Ex. 6b: "Entre os campeões de vendas estão produtos baratos como duas soluções para unhas, na faixa de $\mathrm{R} \$ 2$, e um composto para diminuir a oleosidade da pele, que sai por $\mathrm{R} \$ 5,99$."

Não existe crescimento físico, real e concreto, de um produto (6a), a não ser a partir de análises estatísticas baseadas na situação anterior do produto no mercado. A visualização desse crescimento acontece por meio do desenho gráfico. Diz-se que um produto é "campeão", neste caso "de venda" (6b), a partir de menção a competições que envolvem seres animados. Esse traço é transposto para o domínio da economia, aproximando um conceito abstrato, também com base estatística, a um conceito que pertence às relações humanas.

Ex. 7a: "Gerson Aronson, diretor da G. Aronson, informa que em novembro e dezembro a Philips e a Philco cortaram 5\% os preços, em dólar, da sua linha de televisores."

Ex. 7b: "Segundo ele, o preço dos tecidos no mercado internacional também está muito atraente - até $20 \%$ mais barato do que similares nacionais."

Ex. 7c: "A campanha ajuda, mas não é tudo. O consumidor ainda é influenciado pelo preço dos produtos."

Ex. 7d: "Para eles, os preços continuarão correndo à velocidade atual."

Em 7a, fala-se de "corte de preço" para referir-se à redução nos preços dos produtos. Esse procedimento de transferência de traço semântico é eficaz, porque torna o texto menos denso e complexo 
(ABREU, 1997). Não é possível que os preços sejam literalmente cortados, mas sabe-se qual o resultado concreto de uma ação real que envolva o uso de um objeto cortante, por exemplo. Novamente, em 7b e c, surgem traços animados acrescidos da noção gráficoestatística de quantificação. É a partir dessa noção que são alcançadas as conclusões apresentadas: "preço muito atraente" e "consumidor influenciado pelo preço”. No exemplo 7d, diz-se, metaforicamente, que os preços continuarão aumentando nas mesmas proporções. "Correr" não contém necessariamente o traço animado, mas, como nos casos anteriores, a noção gráfico-estatística continua presente.

Ex. 8a: "Esta informação sacudiu ontem o mercado financeiro e acabou pressionando os juros no mercado futuro (especialmente para setembro e outubro).”

Ex. 8b: "Fechado e sacramentado, o anúncio oficial da entrada da rede Wal-Mart no Brasil será feito até o próximo domingo, por um comunicado ao mercado."

Ex. 8c: "É desse mercado, dizem eles, que a indústria de suco de laranja pronto para beber quer tentar pegar uma fatia. A Parmalat já abocanhou o equivalente a 0,5\%."

Ex. 8d: "O mercado está agitado também pelas mudanças recentes nas grandes cervejarias do país e do exterior."

A noção de mercado possui intrinsecamente traços abstratos. Usa-se essa expressão com relação a referentes situacionais concretos, mas nem mesmo esses referentes se deixariam sacudir, comunicar, permitiriam corte, ou agitação. Ocorre, mais uma vez, a concretização de elementos que possuem alto grau de abstração. Abordam-se questões relativas ao mercado como um objeto físico, dotado de alguns traços animados, como se fosse possível pegá-lo, tocá-lo, manipulá-lo, informá-lo e ainda observar suas reações.

Ex. 9a: "No início de abril, a pole-position estava, aparentemente, com os fundos. A expectativa era de escalada da inflação e dos juros." 
Ex. 9b: "A taxa de inflação foi puxada, ainda, pela aceleração de preços no setor de despesas pessoais (mais 42,8\%). As maiores pressões vieram de cerveja $(51,61 \%)$, cigarros $(39,82 \%)$ e produtos de higiene e beleza”...

A idéia de quantificação por meio da concretização gráficoestatística está presente nos exemplos 9a e b, juntamente com traços animados, para revelar a noção de aumento da taxa de inflação. Em $9 \mathrm{~b}$, esse aumento é provocado por um elemento transformado em agente: as despesas pessoais.

De acordo com a tipologia da metáfora proposta por Lakoff e Johnson (1980), é possível identificar, nos dados, metáforas orientacionais e ontológicas, como nos exemplos seguintes:

"Patrimônio mantém queda." - metáfora orientacional

"Os preços continuarão correndo à velocidade atual." metáfora ontológica

Metáforas conceituais das quais encontrou-se emprego variado e freqüente de expressões metafóricas seriam A ECONOMIA É UMA GUERRA, MAIS É PARA CIMA e MENOS É PARA BAIXO. A primeira delas é concretizada textualmente, nos dados deste estudo, pelas seguintes expressões destacadas:

"Os fabricantes de televisores em cores estão em guerra de preços."

"Com isso, corta custos e ganha mais agressividade nos preços."

"Para Ramos, os importadores não têm condição, a médio e longo prazo, de disputar o mercado de carros 'populares' com as montadoras instaladas no país."

... "'o plano de estabilização provocará aumento do consumo, principalmente entre grupos de menor renda que, pela primeira vez, terão alguma proteção contra a inflação', diz.”

Quanto à metáfora conceitual MAIS É PARA CIMA, identificase sua concretização em expressões como as citadas a seguir. Vale 
enfatizar que MAIS É PARA CIMA nem sempre implica valor positivo. $\mathrm{Na}$ verdade, na área da economia é muito comum que as subidas tenham um impacto social e econômico negativo, o que não resulta em incoerência, pois os conceitos metafóricos perpassam diferentes experiências. Mesmo que o conceito de PARA CIMA seja idêntico em todas as metáforas, as experiências que o fundam são distintas.

"A alta do dólar."

"Expectativa de escalada da inflação."

"A taxa da inflação foi puxada pela aceleração de preços."

MENOS É PARA BAIXO, por sua vez, concretiza-se por meio de expressões como as seguintes. Deve-se lembrar que, como MAIS É PARA CIMA pode ter um valor negativo, MENOS É PARA BAIXO pode ter um valor positivo, em termos econômicos, embora isso não valha como regra.

"A cesta registra queda de 0,66\%."

"A inflação vai cair."

Como se pôde observar, em consonância com as idéias de Abreu (1997), a área da economia é rica em empregos metafóricos como meio de esfriamento textual. Talvez esses usos sejam tão freqüentes em textos da esfera jornalística, porque tornam menos complexas noções que envolvem ampla gama de cálculos numéricoestatísticos que seriam de difícil compreensão ao público leitor do jornal e, assim, não atingiriam seu objetivo.

Quem produz a notícia jornalística - autor, não conhecido do público, que representa uma empresa - parece utilizar expressões metafóricas com o intuito de facilitar o processo de compreensão do texto. Segundo Grimm-Cabral (1994: 16), o escritor pode usar um recurso metafórico para ajudar o leitor a compreender um conceito considerado difícil. O gênero do discurso aqui analisado com relação à metáfora é visto por muitos autores como altamente referencial. No entanto, por meio da análise desta pequena amostra de textos, 
percebe-se a presença de expressões metafóricas. Esse uso se justifica, pois a metáfora pode ser entendida como uma forma de esfriamento textual, e a notícia, considerando sua função social, deve ser um texto de "baixa temperatura".

\section{CONSIDERAÇÕES FINAIS}

Este estudo preliminar permitiu clarear uma série de questões relativas ao emprego de recursos metafóricos nas notícias econômicas. Entre os principais aspectos, pode-se destacar o modo como a metáfora se concretiza nesse gênero discursivo, aparecendo, em nossos dados, com fortes traços orientacionais e interpessoais, conforme a teoria de Lakoff e Johnson (1980).

Segundo a perspectiva bakhtiniana, os gêneros discursivos se constróem sócio-historicamente, fenômeno que atribui a eles certa estabilidade, funcionando assim como um modelo de referência para o escritor e criando um contexto de expectativas para o leitor. Dessa forma, autor e leitor esperam encontrar características semelhantes em textos que constituem um mesmo gênero do discurso.

Embora a notícia jornalística seja considerada como texto com características bastante referenciais, trata-se de um gênero permeado por metáforas. No caso desta investigação, foram identificadas e analisadas metáforas convencionais, uma vez que o critério de busca foi a relação com a palavra-chave selecionada. Eventualmente, os resultados poderiam ser distintos, localizando metáforas deliberadas ou novas, caso os critérios fossem outros.

A metáfora, neste gênero do discurso, parece exercer o papel de facilitador do processo de construção do sentido de concepções altamente abstratas, por meio da utilização de propriedades de um domínio de experiência-fonte em um domínio-alvo. Trata-se de um processo de concretização ou "esfriamento" da informação, considerando o gênero do discurso do qual faz parte, o que implica conhecer os objetivos, o veículo, os valores, bem como o possível grupo de indivíduos envolvidos na situação interativa de comunicação. 
Um aspecto que deve ser ressaltado é o de que, mesmo em textos relativamente mais objetivos, como a notícia, existe emprego de expressões metafóricas com uma freqüência relativamente alta, conforme demonstram as análises aqui realizadas.

\section{NOTAS}

${ }^{1}$ A razão pela qual se decidiu falar, nesta pesquisa, a respeito da notícia especificando a esfera à qual ela pertence, ou seja, a esfera jornalística, é o fato de as notícias poderem pertencer a muitas outras esferas, não consideradas neste trabalho. Pode haver, por exemplo, notícias nas esferas do cotidiano, da indústria, do comércio, como também nas esferas religiosa, escolar, etc.

${ }^{2}$ Lide é o termo aportuguesado do inglês lead, que significa guia, condutor.

${ }^{3}$ Lakoff e Johnson representam as metáforas conceituais com letras maiúsculas.

${ }^{4}$ Todos os exemplos citados são extratos do corpus. Não foi possível, no entanto, resgatar a localização exata das frases, pois houve inúmeras seleções automáticas em que a indicação do dia, mês e ano foram omitidas.

\section{REFERÊNCIAS BIBLIOGRÁFICAS}

ABREU, A. S. Curso de redação. 6. ed. São Paulo: Ática, 1997.

BAKHTIN, M. \& V. N. VOLOSHINOV. Marxismo e filosofia da linguagem: Problemas do método sociológico na ciência da linguagem. Tradução: Michel Lahud e Yara F. Vieira. 2. ed. São Paulo: Hucitec, 1981.

BERBER-SARDINHA, T. Comparing corpora with WordSmith Keywords. The ESPecialist, São Paulo, v. 22, n. 1, p. 87-99, 2001.

FARACO, C. A. O dialogismo como chave de uma antropologia filosófica. In: FARACO, C. A. (Org.) Diálogos com Bakhtin. Curitiba: Universidade Federal do Paraná. 1996. p. 113-126.

FARIA, M. A. O jornal na sala de aula. 9. ed. São Paulo: Contexto, 1997.

FARIA, M. A. Como usar o jornal na sala de aula. São Paulo: Contexto, 1996.

FOlHA DE SÃO PAUlO. Novo manual de redação. 9. ed. São Paulo: Folha de São Paulo, 2000.

FREITAS, M. T. A. Bakhtin e a psicologia. In: FARACO, C. A. (Org.) Diálogos com Bakbtin. Curitiba: Universidade Federal do Paraná, 1996. p. 165-187. 
GIBBS, R. W., Jr. The poetics of mind: figurative thought, language, and understanding. Cambridge: Cambridge University Press, 1994.

GIBBS, R. W., Jr. Cambridge: Cambridge University Press, 1994. Resenha de NARDI, M. I. A. The poetics of mind: figurative thought, language, and understanding. D.E.L.T.A., 13, 2, p. 341-352. 1997.

GRIMM-CABRAL, L. Metáforas e leitura. In: FORTKAMP, M. B., TOMITCH, L. B. (Org.). Aspectos da lingüistica aplicada: estudos em homenagem ao Professor Hilário Bohn. Florianópolis: Insular. 2000. p. 51-71.

GRIMM-CABRAL, L. The role of metaphor in informative texts. 1994. $181 \mathrm{f}$. Tese (Doutorado em Letras opção Língua Inglesa e Lingüística aplicada) - PósGraduação em Inglês e Literatura Correspondente, Universidade Federal de Santa Catarina, Florianópolis.

GUTIERREZ PALACIO, J. Periodismo de opinion. Madri: Paraninfo, 1984. p. 1251, 99-128.

HENDERSON, W. Metaphor in economics. In: COULTHARD, M. Ed. Talking about text: studies presented to David Brazil on his retirement. Birmingham: English Language Research. 1986. p. 109-127.

HOUAISS, A. \& VILlAR, M. S. Dicionário Houaiss da Lingua Portuguesa. Rio de Janeiro: Objetiva, 2001.

LAKOFF, G. The Invariance Hypothesis: is abstract reason based on imageschemas? Cognitive Linguistics, Berlin, New York, v. 1, n. 1, p. 39-74, 1990.

LAKOFF, G. \& JOHNSON, M. Metaphors we live by. Chicago: The University of Chicago Press, 1980. 241 p.

LAKOFF, G. Metáforas da vida cotidiana. Coordenação da tradução Mara Sophia Zanotto. São Paulo: Mercado de Letras; São Paulo: EDUC, 2002. 360 p. Título original: Metaphors we live by.

LAGE, N. Estrutura da notícia. 4. ed. São Paulo: Ática, 1998a.64 p.

LAGE, N. Linguagem jornalística. 6. ed. São Paulo: Ática, 1998b. 78 p.

LAGE, N. A ideologia da notícia. Petrópolis: Vozes, 1979. p. 33-96.

MALTA, J. C. O desenvolvimento da metacognição da metáfora: uma experiência de ensino. 2000. 141 f. Dissertação (Mestrado em Letras) - Pós-Graduação em Letras/Lingüística, Universidade Federal de Santa Catarina, Florianópolis.

MARTIN VIVALDI, G. Generos periodisticos: reportaje, crónica, articulo. 2. ed. Madri: Paraninfo, 1979. p. 23-37, 64-72. 
MARTÍNEZ ALBERTOS, J. L. Redacion periodistica (los estilos y los géneros en la prensa escrita). Barcelona: A.T.E, 1974.

MELO, J. M. Gêneros jornalísticos na Folha de São Paulo. São Paulo: FTD, 1987. p. 1-18.

O GLOBO. Manual de redação e estilo. 26. ed. São Paulo: Globo, 1999. p. 1-38.

RODRIGUES, R. H. A constituição e o funcionamento do gênero jornalístico artigo: cronotopo e dialogismo. 2001a. 347 f. Tese (Doutorado em Lingüística aplicada e Estudos da Linguagem) - Pontifícia Universidade Católica de São Paulo, São Paulo.

RODRIGUES, R. H. A relação entre gênero, enunciado e texto: uma leitura bakhtiniana. In: CONGRESSO NACIONAL DA ABRALIN, 3., Fortaleza. Anais... Fortaleza, 2001b.

RODRIGUES, R. H. Gênero do discurso e cronotopo: a dimensão social constitutiva do gênero. In: SEMINÁRIO NACIONAL SOBRE LINGUAGEM E ENSINO, 3, Pelotas. Anais... Pelotas, 2001c.

RODRIGUES, R. H. O artigo jornalístico e o ensino da produção escrita. In: ROJO, R. (Org.). A prática de linguagem em sala de aula: Praticando os PCNs. São Paulo: EDUC; Campinas: Mercado de Letras, 2000. p. 207-220.

SODRÉ, M.; FERRARI, M. H. Técnica de redação. 3. ed. Rio de Janeiro: Francisco Alves, 1982. p. 5-27, 73-83, 106-109.

SOUZA, A. C. Aspectos da metáfora na notícia: análise de corpus. In: CONFERENCE ON METAPHOR IN LANGUAGE AND THOUGHT. São Paulo, 2002. Comunicação. 